\title{
Who's Afraid of Life After Death?
}

\author{
Neal Grossman, Ph.D. \\ University of Illinois at Chicago
}

ABSTRACT: The evidence for an afterlife is sufficiently strong and compelling that an unbiased person ought to conclude that materialism is a false theory. Yet the academy refuses to examine the evidence, and clings to materialism as if it were $a$ priori true, instead of a posteriori false. I suggest several explanations for the monumental failure of curiosity on the part of academia. First, there is deep confusion between the concepts of evidence and proof. Second, materialism functions as a powerful paradigm that structures the shape of scientific explanations, but is not itself open to question. The third explanation is intellectual arrogance, as the possible existence of disembodied intelligence threatens the materialistic belief that the educated human brain is the highest form of intelligence in existence. Finally, there is a social taboo against belief in an afterlife, as our whole way of life is predicated on materialism and might collapse if near-death experiences, particularly the life review, were accepted as fact.

KEY WORDS: near-death experience; resistance to evidence; survival as an empirical hypothesis; fundamaterialism.

For more than a hundred years there has been a small but persistent effort on the part of dedicated researchers to discover solid empirical evidence that supports the thesis that our mind or consciousness survives the death our physical bodies. Beginning with William James' research on mediumship and culminating in contemporary research on the neardeath experience (NDE), this body of research provides solid ground for believing that the materialist paradigm currently in fashion among academics is severely limited, and fails to account for the accumulated data. Although this evidence has convinced the majority of people who have taken the time to examine it carefully that materialism is no longer an adequate paradigm, the overwhelming majority of academics do not

Neal Grossman, Ph.D., is Associate Professor of Philosophy at the University of Illinois at Chicago. Reprint requests should be addressed to Dr. Grossman at the Department of Philosophy (MC267), 1421 University Hall, University of Illinois at Chicago, 601 South Morgan Street, Chicago, IL 60607-7114; e-mail: Nealg@uic.edu. 
bother to examine the evidence, and seem to believe $a$ priori that materialism must be true.

It is not my purpose here, except for a few examples below, to review the wealth of data that falsifies materialism. Rather, I wish to examine here the academy's failure to examine the evidence-a failure that is especially perplexing when one considers the immense importance the question of an afterlife has for human beings. In this editorial I will take the position that the evidence against materialism has accumulated over the years to the point that it is now reasonable to assert that materialism has been shown to be empirically false; hence, what needs to be explained is the academic establishment's collective refusal to examine the evidence and to see it for what it is. The academic establishment is in the same position today as was the bishop who refused to look through Galileo's telescope. Why is that the case?

Before addressing this question, it is probably incumbent on to me to say a few words about the kind and strength of evidence that refutes materialism. Emily Cook, Bruce Greyson, and Ian Stevenson described "three features of NDEs - enhanced mentation, the experience of seeing the physical body from a different position in space, and paranormal perception - that [they] believe might provide convergent evidence supporting the survival hypothesis" (Cook, Greyson, and Stevenson, 1998, p.377). They then went on to describe 14 cases that satisfied those criteria. From an epistemological perspective, the third criterion, paranormal perception, is the most important. The materialist can, in principle, give no account of how a person acquires veridical information about events remote from his or her body. Consider, for example, the kind of case where the NDEr accurately reports the conversation occurring in the waiting room while his or her body is unconscious in the operating room. There is no way for the relevant information, conveyed in sound waves or light waves, to travel from the waiting room, through corridors and up elevators, to reach the sense organs of the unconscious person. Yet the person wakes from the operation with the information. This kind of case-and there are lots of them-shows quite straightforwardly that there are nonphysical ways in which the mind can acquire information. Hence materialism is false.

Perhaps the "smoking gun" case is the one recently described by Michael Sabom (1998). In this case, the patient had her NDE while her body temperature was lowered to 60 degrees, and all the blood was drained from her body: "her electroencephalogram was silent, her brain-stem response was absent, and no blood flowed through her brain" 
(Sabom, 1998, p.49). A brain in this state cannot create any kind of experience. Yet the patient experienced a profound NDE, which included detailed veridical perception of the operation. Those materialists who believe that consciousness is secreted by the brain, or that the brain is necessary for conscious experience to exist, cannot possibly explain, in their own terms, cases such as this. An impartial observer would have to conclude that not all experience is produced by the brain and that, therefore, the falsity of materialism has been empirically demonstrated. Thus, what needs to be explained is the abysmal failure of the academic establishment to examine this evidence and to embrace the conclusion: materialism is false, and consciousness can and does exist independently of the body.

Moreover, the evidence against materialism comes not only from the NDE, but from other areas of research as well. Both mediumship, which has been extensively investigated since the time of William James, and cases of children, such as those investigated by Stevenson, who have verified memories of past lives, offer an abundance of evidence against materialism. The best epistemological analysis of the evidence was given by Robert Almeder (1992). After a lengthy and detailed discussion of children who appear to remember previous lives, he twitted Stevenson for concluding only that "it is not unreasonable to believe in reincarnation," given the evidence. The proper conclusion, according to Almeder, should be "it is unreasonable to reject belief in reincarnation," given the evidence (Almeder, 1992, p.62). I agree with Almeder.

Our collective irrationality with respect to the wealth of evidence against materialism manifests in two ways: first, by ignoring the evidence, and second, by insisting on overly stringent standards of evidence, which, if adopted, would render any empirical science impossible. The refusal of academics to examine the evidence against materialism is not new. Writing one hundred years ago, William James complained

... I invite eight of my scientific colleagues severally to come to my house at their own time, and sit with a medium for whom the evidence already published in our Proceedings had been most noteworthy. Although it means at worst the waste of the hour for each, five of them decline the adventure. I then beg the "Commission" connected with the chair of a certain learned psychologist in a neighbouring university to examine the same medium, whom Mr. Hodgson and I offer at our own expense to send and leave with them. They also have to be excused from any such entanglement. I advise another psychological friend to look into this medium's case, but he replies that it is useless, for if he should get such results as I report, he would (being suggestible) simply believe himself hallucinated... This friend of mine writes ex cathedra 
on the subject of psychical research, declaring (I need hardly add) that there is nothing in it; ... and one of the five colleagues who declined my invitation is widely quoted as an effective critic of our evidence. So runs the world away! (James, 1986/1869-1909, p.194)

More recently, Michael Grosso reported a similar experience in attempting to get colleagues to read anything on the evidence for life after death:

The type of person I have in mind will come up with weak, if not irrational, excuses for not reading the book I place in his hand. In one case, the argument ran: "It's only words on paper; no reason to take any of it seriously." Another academic said he didn't have the time. "You mean you can't find a few hours to read a book that might change your basic outlook on life and death?" I asked.

How strange that these intelligent people should be not merely indifferent but resistant to the data. It's as if there were a conspiracy against this information, a need to make it harmless, irrelevant, or nonexistent. (Grosso, 1990, pp. 241-242; italics added)

One of my earliest encounters with this kind of academic irrationality occurred more than twenty years ago. I was devouring everything on the near-death experience I could get my hands on, and eager to share what I was discovering with colleagues. It was unbelievable to me how dismissive they were of the evidence. "Drug-induced hallucinations," "last gasp of a dying brain," and "people see what they want to see" were some of the more commonly used phrases. One conversation in particular caused me to see more clearly the fundamental irrationality of academics with respect to evidence against materialism

I asked, "What about people who accurately report the details of their operation?"

"Oh," came the reply, "they probably just subconsciously heard the conversation in the operating room, and their brain subconsciously transposed the audio information into a visual format."

"Well," I responded, "what about cases where people report veridical perception of events remote from their body?"

"Oh, that's just a coincidence or a lucky guess."

Exasperated, I asked, "What will it take, short of having a near-death experience yourself, to convince you that it's real?"

Very nonchalantly, without batting an eye, the response was: "Even if I were to have a near-death experience myself, I would conclude that I was hallucinating, rather than believe that my mind can exist independently of my brain."

He went on to add that dualism-the philosophical thesis that mind and matter are independent substances, neither of which can be reduced 
to the other-is a false theory and that there cannot be evidence for something that is false. This was a momentous experience for me, because here was an educated, intelligent man telling me that he will not give up materialism, no matter what. Even the evidence of his own experience would not cause him to give up materialism.

I realized two things in that moment. First, this experience cured me of any impulse to argue these things with recalcitrant colleagues; it is pointless to argue with someone who tells me that his mind is already made up, and nothing I can say will change it. Second, this experience taught me that it is important to distinguish between (a) materialism as an empirical hypothesis about the nature of the world, which is amenable to evidence one way or the other (this is the hallmark of a scientific hypothesis: that evidence is relevant for its truth or falsity) and (b) materialism as an ideology, or paradigm, about how things "must" be, which is impervious to evidence (this is the hallmark of an unscientific hypothesis: that evidence is not relevant for its truth). My colleague believed in materialism not as a scientific hypothesis that, as a scientific hypothesis, might be false; but rather as dogma and ideology which "must" be true, evidence to the contrary notwithstanding. For him, materialism is the fundamental paradigm in terms of which everything else is explained, but which is not itself open to doubt. I shall coin the term "fundamaterialist" to refer to those who believe that materialism is a necessary truth, not amenable to empirical evidence.

With respect to (a) materialism held as an empirical hypothesis about the world, the evidence against it is overwhelming. With respect to (b) materialism held as an ideology, evidence against it is logically impossible. A complicating factor is that fundamaterialists typically hold the metabelief that their belief in materialism is not ideological, but empirical. That is, they misclassify themselves under (a), while their behavior clearly falls under (b). Debunkers believe that they are being "scientific" in ignoring and rejecting the evidence against materialism. They claim that the evidence is weak, that it is not compelling, that it can be easily explained away by the materialist paradigm. But when asked what kind of evidence it would take to convince them that materialism is empirically false, they are, like my colleague, usually at a loss for what to say. If they are not familiar with the data, they will come up with a criterion of evidence that in fact has already been met. When it is pointed out to them that there exist many well-documented cases that satisfy their proposed criterion, they will simply make their criterion more stringent, and at some point cross the line between the 
reasonable demand for scientific evidence and the unreasonable (and unscientific) demand for logical proof.

This is not a minor point. Fundamaterialism is so deeply ingrained in the academic establishment that most near-death researchers fall prey to it. For, after presenting case after case that would satisfy any reasonable standard of empirical evidence against materialism, even sympathetic researchers almost always deem it necessary to add the disclaimer that their research does not prove that there is life after death. But no scientific hypothesis is ever proven in this sense. Theorems in logic and mathematics can be proved. In science, hypotheses are not proved; rather, empirical evidence renders a given hypothesis more or less probable. There is no logical or mathematical certainty in science. The fundamaterialists are correct in that the hypothesis that consciousness exists independently of the body cannot be proven with mathematical certainty. But neither can any other scientific hypothesis, because empirical science deals with evidence, not proof. Evidence never "proves" a hypothesis; it just makes the hypothesis more probable. And, when evidence for a given hypothesis accumulates to a certain degree, we accept the hypothesis as true. But "true" in this scientific sense never means "proven"; it means very, very probable. In science there is always the possibility that a given hypothesis may turn out to be false. The fundamaterialists will not accept the hypothesis of an afterlife until it is "proven" beyond a logical possibility of being false. That is, they use a concept of proof that belongs in logic and mathematics, not in science. And near-death researchers are playing the fundamaterialists' game when they utter caveats that their research does not prove the hypothesis of an afterlife. What researches should say, in my opinion, is simply that they have amassed sufficient evidence to render the hypothesis of an afterlife very probable, and the hypothesis of materialism very improbable.

In the above paragraphs, I have been using the terms "science" and "scientific" in their epistemological sense. Science is a methodological process of discovering truths about reality. Insofar as science is an objective process of discovery, it is, and must be, metaphysically neutral. Insofar as science is not metaphysically neutral, but instead weds itself to a particular metaphysical theory, such as materialism, it cannot be an objective process for discovery. There is much confusion on this point, because many people equate science with materialist metaphysics, and phenomena that fall outside the scope of such metaphysics, and hence cannot be explained in physical terms, are called "unscientific." This is a most unfortunate usage of the term. For if souls and spirits are in fact 
a part of reality, and science is conceived epistemologically as a systematic investigation of reality, then there is no reason why science cannot devise appropriate methods to investigate souls and spirits. But if science is defined in terms of materialist metaphysics, then, if souls and spirits are real, science, thus defined, will not be able to deal with them. But this would not be because souls and spirits are unreal, but rather because this definition of science in terms of materialist metaphysics has semantically excluded nonphysical realities from it scope.

Peter and Elizabeth Fenwick used the term "science" in this metaphysical sense when they wrote:

So far we've taken a largely scientific, and therefore a rather limited view of the NDE. We've been looking at mechanism, and almost everything we have said has been based on the assumption that the NDE takes place in or is constructed by the brain. We've confined 'mind' to the brain because, scientifically, ... we have no other option. When the brain dies, the mind dies; the scientific view does not allow for the possibility of a soul, or for any form of personal survival after death.

It is only by looking at some non-scientific views that we might find a wider explanation of the NDE... (Fenwick and Fenwick, 1997, p.249)

If the term "materialistic" is substituted for "scientific," then the above passage is an accurate statement with which I have no quarrel. The last sentence becomes: "It is only by looking at nonmaterialistic views that we might find a wider explanation of the NDE..." And this is absolutely correct. Materialism is a woefully inadequate framework in terms of which to understand the NDE. And, I wish to insist, it is science itself, understood epistemologically as a metaphysically neutral method of inquiry, that has discovered the limitations of materialism. After all, the primary researchers in the field are not philosophers or theologians, but well-trained scientists and physicians, who, using standard scientific methodology, have been forced by their data to conclude that materialism cannot be the whole truth.

I stress this semantic point about how the word "scientific" should be used in part because the term carries a lot of emotional weight. To be labeled "unscientific" is sufficient for having one's work or one's self dismissed and ignored by the academic establishment. And I think this is part of the reason academics are in fact dismissive of the research on the NDE. The reasoning goes something like this: to be scientific is good; to be unscientific is bad. Science equals materialism. To believe in souls and spirits, or even to talk about souls and spirits, is to talk about and/or believe in something that is not materialistic. Therefore it is unscientific, which is bad, and hence we should not waste any time 
on it. I believe that most of my colleagues think like this. The false premise upon which the argument hangs is the equating of science with materialism, an equation so deeply ingrained that it is difficult to root out. But I think even the most die-hard materialist ought to grant the following argument: If souls are real, that is, if nonmaterial objects exist, then it should be possible to study them, to acquire data about them, to construct generalizations and theories about them, and so on; which is to say, it should be possible to study them scientifically. Hence science ought to be construed as a method of inquiry only, not as a metaphysical theory that stipulates by definition what there is, and what can or cannot exist.

I wish to turn my attention now to the discipline of philosophy. It would seem that, of all the disciplines, philosophy ought to be most interested in, and meticulously study, all the research on the NDE. After all, is philosophy not supposed to be concerned with questions of ultimate meaning, of the purpose of life, of the relation between mind and body, of God, and so on? NDE research has data that are directly relevant to all of these questions. So how is it possible that philosophers have collectively managed to ignore and even ridicule this research? To those outside of academic philosophy, it may come as a surprise to learn the great majority of academic philosophers are atheists and materialists. While, as I have argued above, they incorrectly use science to support their materialism, they systematically ignore the findings of science-which I take near-death research to be-that refute their materialism. Since their materialism is not empirically based, I call it fundamaterialism, to make explicit comparison with fundamentalism in religion. Fundamentalism connotes an attitude of certainty towards one's core belief. Just as the fundamentalist Christian is absolutely certain that the world was created in the manner described by the Bible-fossil evidence notwithstanding-so also the fundamaterialist is absolutely certain that there exists nothing that is not made up of matter-NDEs and other evidence notwithstanding. In fact, and this is the crucial point, their respective beliefs have nothing to do with evidence. As my fundamaterialist colleague put it: "There can't be evidence for something that's false."

As a brief aside, I believe there are some interesting parallels to be drawn by comparing fundamaterialists' and fundamentalists' attitudes towards data that challenge their respective worldviews. Fundamentalists are just as inventive in explaining away fossil evidence as fundamaterialists - at least those who bother to look at paranormal research-are at explaining away near-death research. One particularly 
ingenious fundamentalist explanation is that, when God created the world some 5000 years ago, He created it with fossils and dinosaur bones in place, to make it look as if the world were older, as a sort of test of our faith. The Creationist then challenges the evolutionary scientist to "prove" that God did not in fact create the world in this way. One does not need to be an astute logician to see that the Creationist's hypothesis is unfalsifiable in principle, hence unscientific. Hence, the evolutionary scientist does not need to show-because it cannot in principle be shown-that God did not create the world with the fossil evidence in place. The arguments of those fundamaterialists who look at the evidence from paranormal research are just as convoluted, involving unfalsifiable premises, confusing evidence with proof, and so one. See Almeder's book cited above for a more detailed examination of some of the convolutions the fundamaterialists must undergo in order to save their materialism.

And, more surprisingly, even those philosophers who are not materialists refuse to look at the data. One would think that a Cartesian dualist, or a Platonist, would eagerly devour the wealth of data that strongly support their point of view. I would like to share a few more personal experiences that highlight some of the attitudes involved. In the late $1970 \mathrm{~s}$, when the early research on the NDE was just being published, I was involved in team-teaching a course with one of the campus chaplains. Excitedly, I shared what I was learning about the NDE with the chaplain, thinking that he would welcome empirical data that, at the very least, constituted strong prima facie evidence for much of what he believed in-soul, afterlife, ultimate responsibility for one's actions, Higher Power, and so on. To my astonishment, he was just as dismissive of the evidence as was my fundamaterialist colleague. When I questioned him about why he was so resistant to the data, he said, in effect, that his belief in God and the afterlife is based on faith, and if these things were decidable empirically, there would be no room left for faith, which for him was the foundation of his religious convictions.

I knew then that the NDE was between a rock and a hard place, as far as being taken seriously by the two disciplines, philosophy and theology, that should be the most interested in it. On the one hand, fundamaterialist philosophers believe in the truth of materialism a priori; empirical evidence is not relevant to them, and they are committed to ignoring and/or debunking anything that looks like evidence. On the other hand, theologians and other intellectuals who do believe in an afterlife tend to base their belief on faith, which they feel would be seriously undermined if empirical evidence were relevant to their beliefs. 
Moreover, once theologists and religionists open the door to empirical evidence, they allow the possibility that the evidence may contradict some aspects of what was believed solely on the basis of faith. Indeed, this has already happened. The evidence from the NDE, for example, suggests that God is not vengeful, does not judge us or condemn us, and is not angry at us for our "sins"; there is judgment, to be sure, but the reports appear to be in agreement that all judgment comes from within the individual, not from the Being of Light. It seems, in fact, that all God is capable of giving us is unconditional love. Because the concept of an all-loving, nonjudgmental God contradicts and undermines the teachings of some religious denominations, it is no wonder that some religious fundamentalists are up in arms about the NDE.

One more story: a few years ago, a Plato scholar from England gave a colloquium at my university. Afterwards, I found myself sitting next to him at dinner, and he politely asked me what my interests were in philosophy. I replied that I was interested in examining the various kinds of evidence suggestive of an afterlife. He, assuming falsely that my interest was in debunking the paranormal, proceeded to tell us of a recent lecture he had attended in England. The lecturer, he said (with a slight sneer of contemptuous ridicule that only the British have truly perfected) was a certain neuropsychiatrist who talked about the NDE, and (with heightened tone of ridicule) actually believed that it was real. Even though I am quite used to the limitations of my metaphysically challenged colleagues, his attitude surprised me. In the first place, here was a Plato scholar, who, like the chaplain, was summarily dismissive of even the possibility that there could be evidence that Plato's views, the views of the philosopher about whom he is an expert, might actually be true. Inasmuch as the first recorded NDE is at the end of Book 10 of Plato's Republic (1953/4th century B.C.), I would have thought that a Plato scholar would at the very least be curious about it. But even more disturbing to me was his implied reasoning. Whenever I hear that a highly trained scientist has studied some sort of esoteric phenomenon, and has come to the conclusion, based on research, that there is something to it, such as James on mediumship or Stevenson on reincarnation, or John Mack on UFOs or Brian Weiss on past-life regressions, my curiosity is piqued, and I want to investigate. My reasoning is that, if respectable, well-trained scientists have concluded that there is something to it, then maybe there $i s$, and I proceed to read what they have to say. But my colleague, the Plato scholar, was reasoning quite differently: if a respectable, well-trained neuropsychiatrist has come to the conclusion that there might be life after death, what this shows is not 
that there might be any empirical reason to believe in an afterlife, but rather, that even a rigorous training in neuropsychiatry cannot protect an individual from believing in such foolish absurdities as an afterlife. This is the reasoning of a closed mind. With respect to the question of an afterlife, his mind was already made up; like most academic philosophers, he believed $a$ priori that there is no afterlife, and since there can be no evidence for something that does not exist, anyone who believes otherwise betrays a mind that has fallen victim to superstition, wishful and fuzzy thinking, irrationality, and so forth.

One conclusion I have come to over the years is that both the atheist and the believer, from the fundamaterialist to the fundamentalist, share something in common. In fact, from an epistemological perspective, what they have in common is much more significant than what they disagree about. What they agree about is this: beliefs pertaining to the possible existence of a transcendent reality-God, soul, afterlife, and so on-are based on faith, not fact. If this is true, then there can be no factual evidence that pertains to such beliefs. This metabelief-that beliefs about a transcendent reality cannot be empirically based-is so deeply entrenched in our culture that it has the status of a taboo. The taboo is very democratic in that it allows everyone to believe whatever he or she wants to believe about such matters. This allows fundamaterialists to feel comfortable in their conviction that reason is on their side, that there is no afterlife, and that those who believe otherwise have fallen prey to the forces of irrationality and wishful thinking. But it also allows fundamentalists to feel comfortable in their conviction that they have God on their side, and that those who believe otherwise have fallen prey to the forces of evil. Thus, although the fundamentalist and the fundamaterialist are on opposite extremes of the spectrum of possible attitudes towards an afterlife, their extreme positions unite them as strange bedfellows in their battles against the possibility that there are matters of fact about the afterlife that empirical research might discover. The very suggestion that empirical research might be relevant to beliefs pertaining to a transcendent reality - that such beliefs are subject to empirical constraint-runs strongly against this taboo, and is hence very threatening to most elements of our culture.

So, at the very least, there is a failure of curiosity among the academic establishment with respect to a large body of data suggestive of an afterlife. And if I am right, if, to paraphrase Almeder, it is irrational not to believe in a transcendent reality, given the evidence, then academia is permeated by a widespread and recalcitrant irrationality that blinds it to the findings of science. Now, the term "irrational" has a wide range 
of meanings, and there is no doubt room for differences of opinion with respect to what constitutes irrational and illogical thinking. But everyone agrees that the domain of rational discourse is structured by basic rules of logic. Those who, while defending their own cherished beliefs, violate these rules may be fairly said to be behaving irrationally. Fundamaterialists, like fundamentalists, are so self-righteously certain of the truth of their beliefs, that they are often blind to the elementary logical errors they commit in defense of their beliefs. James, as far as I know, was the first paranormal researcher to point that out. James got so upset about an 1898 editorial in Science debunking mediumship that he wrote a scathing reply exposing some of the errors of logic, which is worth quoting at some length:

Any hearing for such phenomena [mediumship] is so hard to get from scientific readers that one who believes them worthy of careful study is in duty bound to resent such contemptuous public notice of them in high quarters as would still further encourage the fashion of their neglect.

I say hearing; I don't say fair hearing. Still less do I speak of fair treatment in the broad meaning of the term. The scientific mind is ... painfully drilled to fairness and logic in discussing orthodox phenomena. But in such mere matters of superstition as a medium's trances it feels so confident of impunity and indulgence whatever it may say, provided it be only contemptuous enough, that it fairly revels in the untrained barbarians' arsenal of logical weapons, including all the various sophisms enumerated in the [logic] books.

Your own comments seem to me an excellent illustration of this fact. If one wishes to refute a man who asserts that some A's are B's, the ordinary rule of logic is that one must not show that some other A's are not B's-one must show him either that those first A's themselves are not B's, or else that no A possibly can be a B. Now Mr. Hodgson comes forward asserting that many of Mrs. Piper's trances show supernatural knowledge. You thereupon pick out from his report five instances from his report in which they showed nothing of the kind. You thereupon wittily remark, "We have piped unto you but ye have not danced," and you sign your name with an air of finality, as if nothing more in the way of refutation were needful and as if what earlier in the article you call "the trivial character of the evidence..." were now sufficiently displayed.

If, my dear sir, you were teaching Logic to a class of students, should you, or should you not, consider this a good instance by which to illustrate the style of reasoning termed "irrelevant conclusion," or ignoratio elenchi, in the chapter on fallacies? I myself think it an extraordinarily perfect instance.

And what name should you assign the fallacy by which you quote one of those five sitters as saying that he himself got nothing from the medium "but a few preposterous compliments," whilst you leave 
unquoted the larger part of his report, relating the inexplicable knowledge which the medium showed of the family affairs of his wife...? I am not sure that the logic books contain any technical name for the fallacy here, but in legal language it is sometimes called suppressio veri, sometimes something still less polite....

I am sure that you have committed these fallacies with the best of scientific consciences. They are fallacies into which, of course, you would have been in no possible danger of falling in any other sort of matter than this. In our dealings with the insane the usual moral rules don't apply. Mediums are scientific outlaws, and their defendants are quasiinsane. Any stick is good enough to beat dogs of that stripe with. So in perfect innocence you permitted yourself the liberties I point out. (James, 1986/1869-1909, p.184)

James' criticisms are as appropriate today as they were one hundred years ago. In fact, the two kinds of logical errors that James identified are probably the ones most frequently used by the fundamaterialists today. Yet James clearly indicated here that it is only with respect to the issue of empirical support for an afterlife that "the scientific mind...drilled to fairness and logic in discussing orthodox phenomena" abandons both fairness and logic, and instead "revels in the untrained barbarians' arsenal of logical weapons, including all the various sophisms enumerated in the books."

Why is this the case? Why is it the case that otherwise rational people, when it comes to discussing empirical evidence for dualism, cheerfully commit all sorts of logical errors - errors that they would never let their students or colleagues get away with. I think there are three interrelated factors, or causes, that converge to generate academia's collective irrationality with respect to this issue: (a) resistance to paradigm change, (b) intellectual arrogance, and (c) social taboo.

The first of these factors is resistance to paradigm change. Ever since the publication of Thomas Kuhn's The Structure of Scientific Revolutions (1962), the concept of a paradigm has been a familiar, useful, albeit sometimes controversial, tool. The concept of a paradigm helps us considerably in understanding scientific revolutions, when dramatic changes occur involving deep-rooted assumptions about how things are or how things must be. All academics matriculate within the context of a specific discipline that trains its practitioners to think in terms of the currently operating paradigm. Once the operating paradigm has been internalized in the mind of the individual, other, competing paradigms appear wrong and/or foolish. For example, I seem to remember, as a graduate student, spending a pleasant afternoon with other graduate students cheerfully ridiculing phenomenology, which is a different 
way of approaching philosophy than the analytic paradigm dominant in America. None of us had read anything about phenomenology, or understood what it was about, yet to us it was meaningless gibberish, foolish French philosophy. Examples, historical and personal, could be multiplied without limit. Indeed, professional meetings, both in science and humanities, not infrequently degenerate into mere debunking sessions. It seems there is something very deep in us humans that causes us to dismiss and ridicule any way of thinking different from our own. There is a natural resistance to forms of thinking that differs from what was internalized during the educational process.

Academic philosophers matriculate within a paradigm that is largely atheistic, materialistic, and reductionistic. There is no God; only material objects and processes exist; and human experience and behavior are to be explicated mechanically in terms of brain states. Books with the terms "mind" or "consciousness" in their title, for example, tend to have as their primary goal the reduction of mental and conscious experience to neurophysiology. To one who has internalized this paradigm, this way of approaching things appears to be right, reasonable, objective, and sensible. The paradigm itself is rarely questioned; it is the very water in which the academic philosopher swims, which is why it is so difficult for one who is immersed in the paradigm to see it as a paradigm, rather than as the way things "must be." Someone operating out of a different paradigm appears to be out of touch with reality, irrational, and so forth. So, one of the forces that cause academics to ignore, dismiss, and ridicule the evidence for an afterlife is the paradigm the individual academic has internalized. The force of a well-entrenched paradigm has, throughout history, always caused scientists and humanists actively to resist paradigms, theories and hypotheses different from their own, as well as information that runs counter to the general contours of their own paradigm. Indeed, I think the concept of a paradigm partly explains why philosophers are, as a whole, much more resistant to the concept of an afterlife than are scientists. (It is scientists, not philosophers, who are actively engaged in this research.) It is because atheism plays a much more central role in the contemporary philosopher's paradigm than it does in the scientist's.

The second factor is intellectual arrogance. In addition to the normal kind of resistance with which any paradigm defends itself against change, the atheist paradigm of academia generally, and of philosophy in particular, is especially threatened by the findings of paranormal research. This is because intellectuals like to regard themselves as the highest manifestation of intelligence on the planet, if not in the 
universe. Embracing an evolutionary model according to which consciousness is correlated with brain development, intellectuals regard the human brain as the highest development of evolutionary forces, and an educated human brain as the highest of the high. Intellectuals like to feel that they are riding atop the crest of the evolutionary wave. This intellectual smugness is greatly threatened by paranormal research, especially the NDE, the results of which strongly suggest (I am tempted to say "clearly show" instead of "strongly suggest") that the human intellect is by no means the highest form of intelligence. The Being of Light is Itself often described as infinite intelligence and love; moreover, intermediate between the humans and God there appear to many forms of disembodied intelligence greatly superior to our own. And furthermore, NDErs report that they feel themselves to be more alive and intelligent while out of the body than when in the body. Near-death research seems to confirm Plato's view that the body acts as a damper on the soul's native intelligence, weighing it down, so to speak, such that the soul is not able to manifest its full intelligence as long as it is embodied in material form.

All this is deeply unsettling to us academics. When we were younger, we may have been poor at sports, we may have been frequently teased by other children for being "squares" or "nerds." But we were smart, and our whole sense of self-worth was tied up in being smart. We were praised by our teachers for getting A's, and we worked hard to achieve the highest possible academic honors and rewards. It is thus quite natural for us to desire theories that support and justify those qualities that are strongest in us. It is therefore very comforting, although blatantly self-serving, to embrace a paradigm according to which we intellectuals are the most highly evolved beings in the universe, or, at least, on the planet. So to ask us to take seriously current near-death research is to ask us to entertain not only the possibility that the atheist paradigm in terms of which we were raised and educated might be inadequate, but also that human intelligence, of which we academics are the supreme manifestation, is not the highest form of intelligence in Creation (and may very well be among the lowest). No wonder there is so much resistance!

The third factor is social and cultural taboo. This is the most serious and powerful source of resistance, because it involves not only the university system, but our whole culture, indeed, our whole way of life. Despite avowals to the contrary, we live in a completely atheistic and irreligious culture. To be sure, most people profess a belief in a Higher Power of some sort, and many people attend religious services regularly, 
but religion, by which I mean religious values, plays no role in shaping the economic and political forces that structure and control our culture. Let me explain: the primary religious value, common to almost all of the world's religions, is love. The religions of the world largely agree that Divine Love is the force that creates and sustains our world, and that our primary purpose while embodied is to grow in our ability to understand and express this love. The world's religions generally advocate that we practice compassion and forgiveness towards others, that we treat people as ends in themselves, and that we not value material possessions. The "good life," according to most religions, consists not in the pursuit of wealth, reputation, or power, but rather in the pursuit of right relationship with the Divine. However, the values of our culture are diametrically opposed to the values of religion. Success in our culture is measured by wealth, reputation, and power; and the desires requisite for obtaining this success are greed and ambition. Religious values have been safely shunted off to one hour a week on Sunday morning, where they are completely ineffective in mitigating the forces of greed and ambition that drive our culture economically. The primary religious values of love and compassion play no role in shaping the economic and political life of our culture. Politicians and corporations seek only to win fame and fortune for themselves; they do not value kindness, they do not seek to share their wealth, and most importantly, they, like everyone else in our culture, measure their self worth according to their wealth, status, and reputation. No one gets rich by being kind to competitors; no one gains political office by being loving towards opponents. Religious values may be paid lip service, but they are inoperative in our culture. Indeed, they are fundamentally incompatible with the values that do, in fact, drive our culture. And by "culture" I mean not only the corporate and political culture, but popular culture as well. Consider, for example, the value of forgiveness, common to almost all religions. In what percent of our movies are the protagonists heroes because they have successfully applied this value and have forgiven their enemies? Compare this with the percentage of movies in which the protagonists are heroes because they successfully applied the opposite value of vengeance and destroyed their enemies.

The reader can probably already see where I am going with this. Research on the NDE has yielded the following unambiguous conclusion. NDErs confirm the basic values of the world's religions. The purpose of life, most NDErs agree, is divine knowledge and love. Studies on the transformative effect of the NDE show that the cultural values of wealth, status, and material possessions become much less important, 
and the perennial religious values of love, caring for others, and acquiring knowledge about the divine ascend to greater importance. That is, the studies show that NDErs not only verbally profess the values of love and knowledge, but they tend to operate in accordance with these values, if not entirely, then at least more so than before. As long as religious values are presented as merely religious values, then it is easy for popular culture to ignore them or give them minimal lip service on Sunday mornings. But if these same religious values are presented as empirically verified scientific facts, then everything changes. If the belief in an afterlife were to be accepted, not on the basis of faith, nor on the basis of speculative theology, but as a well-confirmed scientific hypothesis, then this could not be ignored by our culture. In fact, it would mean the end of our culture in its present form. Consider the following scenario: Further near-death research confirms in great detail what has already been established, many more cases of verified veridical perceptions while "out of body" are collected and documented, advancing medical technology makes possible many more "smoking gun" cases of the type discussed above, longitudinal studies on NDErs confirm the already observed behavioral changes aligned with their newly acquired (or recently reinforced) spiritual values, and so forth. The studies are replicated in different cultures, with the same results. Eventually, the weight of evidence begins to set in, and scientists are ready to announce to the world, if not as fact, then at least as highly confirmed scientific hypotheses:

(1) There is an afterlife.

(2) Our real identity is not our body, but our mind or consciousness.

(3) Although the details of the afterlife are not known, we are reasonably certain that everyone will experience a life review, in which individuals experience not only every event and every emotion of their lives, but also, the effects their behavior, positive or negative, has had on others. The usual defense mechanisms with which we hide from ourselves our sometimes cruel and less than compassionate behavior towards others seem not to operate during the life review.

(4) The purpose of life is love and knowledge-to learn as much as possible about both this world and the transcendent world, and to grow in our ability to feel kindness and compassion towards all beings.

(5) A consequence of the life review is that it appears to be a great disadvantage to oneself to harm another person, either physically 
or psychologically, since whatever pain one inflicts on another is experienced as one's own in the life-review.

This scenario is by no means far-fetched. I believe there is already sufficient evidence to present the above propositions as "probable," or "more likely than not," based on the evidence. Further studies will only increase the probability. When this happens, the fallout will be revolutionary. When these findings are announced by scientists, it will become impossible for our culture to do business as usual, either economically or politically, or in the universities. For our universities are institutions of our culture and, as such, manifest and perpetuate the values of our culture. It would be interesting to speculate what an economy or a university that tries to align itself with the above five empirical hypotheses might look like, but that is a project well beyond the scope of this paper. It is sufficient for our present purposes simply to note that acceptance of the findings of near-death researchers would mark the beginning of the end of a culture whose driving forces have been greed and ambition, and which measures success in terms of material possessions, wealth, reputation, and social status. The present culture, therefore, has an enormous vested interest in undermining near-death research, which it does through ignoring, debunking, and otherwise marginalizing the research. More subtly, our culture has created an atmosphere of "taboo," for want of a better name, around any serious discussions of spirituality. This is why we tend to feel uneasy and awkward in discussing these things with colleagues. We can discuss spirituality in the academy as something that other people believe, but not as something for which there could be empirical evidence and that might be empirically true. Even the former is difficult. I remember attending a conference on Baruch Spinoza some years ago. A member of the audience wanted to ask the speaker whether he thought Spinoza was a mystic. But the questioner could not bring himself to utter the word "mystic." He stuttered and stammered until someone else asked the question for him. The taboo against spirituality is so strong in academic philosophy, that we feel awkward and embarrassed even to say the word "mystic." And this is why I say that something like a taboo is operating here, something we have all internalized, which generates feelings of unease and anxiety whenever spiritually is discussed as something that might be true, rather than merely intellectually, as sociology, history, psychology, or literature.

To avoid these feelings of discomfort and anxiety generated by the taboo, academics try to protect themselves by employing the same 
strategies that everyone uses to avoid anxiety. The first strategy is denial. By paying no attention to the research, by ignoring it and dismissing it a priori, the academic is spared the uncomfortable feelings that would arise from violating the taboo. The second strategy is to debunk, to explain away, and to otherwise marginalize the research, and sometimes even the researchers themselves.

I believe I have identified several of the major factors involved in academia's collective refusal to take seriously the results of research into the paranormal. Those disciplines that would be most affected by this research, such as philosophy and psychology, are the most resistant to the data, because the data call into question their most fundamental presuppositions of what a person is and of what life is all about. There is thus much for academics generally, and philosophers and psychologists especially, to fear in this research. I would urge those researchers who have become personally convinced, based on their own empirical studies, that materialism is false and that mind can and does exist independent of body, to assert their findings boldly as scientific, not merely as their own personal beliefs: science has shown that materialism is false and that the best hypothesis that fits their data is the hypothesis that mind exists independently of the body. Let us not play the fundamaterialist's game of confusing the concept of evidence with the concept of proof by hedging our findings with disclaimers. For the fundamaterialists and debunkers would have us believe that the burden of proof is on us to first disprove every alternative hypothesis they can imagine. To accept their unreasonable demands puts researchers in the same epistemological position that Charles Darwin would be in if he had accepted the Creationists' claim that the theory of evolution was not well established unless he first was able to prove that God did not create the world 5000 years ago, complete with fossils and dinosaur bones, in order to test our faith later on. We must accept Almeder's conclusion that, based on a detailed examination of Stevenson's cases of children who remember past lives, "from a philosophical (epistemological) point of view, the belief in reincarnation (and hence in a mind or soul which exists independent of the body) is certainly as well-established as, if not better than, say, the belief in the past existence of dinosaurs" (Almeder, 1992, p. 2, parentheses added).

I would like to close by telling a story I heard about C. D. Broad. Broad was a famous British philosopher in mid-20th century. He served as president of the British Society for Psychical Research, and was the last philosopher with an international reputation who believed there was something to psychical research. Towards the end of his life he 
was asked how he would feel if he found himself still present after his body had died. He replied that he would feel more disappointed than surprised. Not surprised, because his investigations led him to conclude that an afterlife was more likely than not. But why disappointed? His reply was disarmingly honest. He said, in effect, that he had had a good life: he was comfortable materially, and he enjoyed admiration and respect from students and colleagues. There is no guarantee that his status, reputation, and comfort would carry over intact into the afterlife. The rules by which success is measured in the afterlife might be quite different from the rules according to which success is measured in this life. And indeed, near-death research suggests that Broad's fears were well founded, that "success" by afterlife standards is measured, not in terms of publications, grants, or reputation, but rather by acts of kindness and compassion to others. Perhaps those whose sense of self-worth arises primarily from their status within academia have, as Broad so eloquently expressed, something to fear from the findings of near-death research.

\section{References}

Almeder, R. (1992). Death and personal survival. Lanham, MD: Rowman and Littlefield.

Cook, E. W., Greyson, B., and Stevenson, I. (1998). Do any near-death experiences provide evidence of survival of human personality after death? Relevant features and illustrative case reports. Journal of Scientific Exploration, 12, 377-406.

Fenwick, P.,and Fenwick, E. (1997). The truth in the light: An investigation of over 300 near-death experiences. New York, NY: Berkley Books.

Grosso, M. (1990). Fear of life after death. In Doore, G. (Ed.), What survives? Contemporary explorations of life after death (pp. 241-254). Los Angeles, CA: Tarcher

James, W. (1986). The works of William James: Essays in psychical research. Cambridge, MA: Harvard University Press. (Original works published 1869-1909)

Kuhn, T. (1962). The structure of scientific revolutions. Chicago, IL: University of Chicago Press.

Plato. (1953). The republic (Book 10). Cambridge, MA: Harvard University Press. (Original work written in 4th century B.C.)

Sabom, M. (1998). Light and death: One doctor's fascinating account of near-death experiences. Grand Rapids, MI: Zondervan. 